\title{
BMJ Open Pentoxifylline for the prevention of contrast-induced nephropathy: systematic review and meta-analysis of randomised controlled trials
}

\author{
Ling Wei, ${ }^{1}$ Weizhi Zhang, ${ }^{2}$ Yifeng Yang, ${ }^{2}$ Dongping Li (D) ${ }^{2}$
}

To cite: Wei L, Zhang W, Yang Y, et al. Pentoxifylline for the prevention of contrastinduced nephropathy: systematic review and meta-analysis of randomised controlled trials. BMJ Open 2021;11:e043436. doi:10.1136/ bmjopen-2020-043436

- Prepublication history and additional supplemental material for this paper are available online. To view these files, please visit the journal online (http://dx.doi.org/10.1136/ bmjopen-2020-043436).

Received 04 August 2020 Revised 20 January 2021 Accepted 24 March 2021
Check for updates

(c) Author(s) (or their employer(s)) 2021. Re-use permitted under CC BY-NC. No commercial re-use. See rights and permissions. Published by BMJ.

${ }^{1}$ Department of Nephrology, Second Xiangya Hospital, Changsha, China

2Department of Cardiothoracic Surgery, Second Xiangya Hospital, Changsha, China

Correspondence to Dr Dongping Li; dongpingli@csu.edu.cn

\section{ABSTRACT}

Objectives To summarise current evidence on the use of pentoxifylline (PTX) to prevent contrast-induced nephropathy (CIN).

Methods The PubMed, Embase and CENTRAL databases were searched for randomised controlled trials including patients with and without PTX undergoing contrast media exposure. We analysed the incidence of CIN and serum creatinine changes before and after contrast media exposure. All statistical analyses were conducted with Review Manager V.5.3.

Results We finally enrolled in seven randomised controlled trials with a total of 1484 patients in this analysis. All of seven included studies were performed in patients undergoing angioplasty or stenting. The overall rates of CIN were $8.8 \%$ and $10.4 \%$ in the PTX groups and control groups, respectively. However, no significant reduction in the CIN rate was observed in the patients treated with PTX compared with the control groups (OR $0.81,95 \% \mathrm{Cl} 0.57$ to $1.13, \mathrm{I}^{2}=0, \mathrm{p}=0.21$ ). All studies reported no hospital mortality and the new requirement for dialysis during the trials.

Conclusion Perioperative administration of PTX to patients undergoing angioplasty did not significantly reduce the development of CIN but showed some weak tendency of lower serum creatinine increase. Based on the available trials, the evidence does not support the administration of PTX for the prevention of CIN. More trials with larger sample sizes are needed to evaluate the role of PTX in CIN prevention.

\section{INTRODUCTION}

Contrast-induced acute kidney injury (AKI), which is also known as contrast-induced nephropathy (CIN), is defined as the development of AKI following contrast medium exposure, without an alternative aetiology. ${ }^{1}$ With the wide application of cardiac catheterisations and nearly 30 million doses of contrast media injection annually, ${ }^{2} \mathrm{CIN}$ constitutes the third leading cause of hospital-acquired AKI. ${ }^{3}$ CIN is associated with the in-hospital need for dialysis, long-term kidney failure and overall mortality and consequently prolongs hospital stay and increases the cost of hospitalisation. ${ }^{4}$

\section{Strengths and limitations of this study}

- This is the first meta-analysis to summarise current evidence of pentoxifylline for the prevention of contrast-induced nephropathy.

- The results were reported in accordance with the Preferred Reporting Items for Systematic Reviews and Meta-Analyses checklist and Cochrane handbook

- Given the small number of trials included in each analysis, we failed to assess publication bias and small study effects with funnel plots.

Even if serum creatinine (Scr) would recover to the baseline quickly in most CIN patients, these patients still suffer worse long-term outcomes than those without CIN..$^{5}$ In light of the vast threat to people's health and public costs, it has become imperative to research the prevention of CIN.

Pentoxifylline (PTX) is a methyl-xanthine derivative with powerful antioxidative, antiinflammatory and anti-immunity properties. It is generally used to treat peripheral vascular diseases. PTX improves the flexibility and oxygen delivery capacity of red blood cells, resulting in improved haemodynamics. In addition, studies in animal models showed that PTX could effectively attenuate kidney injury induced by contrast media or Escherichia coli. ${ }^{6}$ In fact, several clinical trials have suggested that PTX may be a potential candidate for renal protection. ${ }^{8-10}$

PTX has been investigated in randomised controlled trials (RCTs) as a potential agent to prevent CIN ${ }^{11-17}$ However, neither systematic reviews nor meta-analyses have been conducted to date to the best of our knowledge. Therefore, we performed this systematic review and meta-analysis of currently available RCTs to summarise and evaluate the renal protective capacity of PTX under contrast media stress. 


\section{MATERIAL AND METHODS}

\section{Search strategy}

We searched electronic databases (PubMed, Embase and Cochrane Central Register of Controlled Trials (Central)) for potential clinical trials up to 29 June 2020 with no language restriction, using combinations of the main terms 'contrast-induced nephropathy' and 'pentoxifylline'. The details of the search strategy are shown in online supplemental appendix 1. Two authors (LW and DL) performed the literature search independently. We also checked relevant reviews and the reference lists of the original articles for further suitable publications.

\section{Study selection}

LW and DL independently screened the titles, abstracts or full texts and assessed their eligibility. We included studies that met the following criteria: RCTs enrolled population underwent contrast media exposure, trials used PTX for prevention of CIN and trials reported CIN rate and/or Scr change after exposure. The exclusion criteria were: animal studies, non-RCTs and lack of necessary data. Any disagreements were resolved by discussion with a third author (WZ).

\section{Data extraction}

Two independent reviewers (LW and DL) extracted data from each eligible study. Data extracted from studies included study characteristics, patient characteristics, details regarding PTX groups and control groups, and outcome assessments. Outcomes of interest for this study were the incidence of CIN and Scr changes after exposure.

\section{Risk of bias}

The risk of bias was assessed through the Cochrane Collaboration Tool. Six domains were evaluated: sequence generation for randomisation, allocation concealment, blinding, incomplete outcome data, selective outcome reporting and other sources of bias. According to Cochrane Handbook, ${ }^{18}$ The risk of biases are classified into three categories: low risk, unclear risk and high risk. Low risk meant all categories were classified as low risk. Unclear risk means one category was classified as unclear risk. High risk means high risk of bias in one or more categories or an unclear risk in two or more categories.

\section{Outcomes}

The primary outcome was the incidence of CIN, defined as a minimum $0.5 \mathrm{mg} / \mathrm{dL}$ or $25 \%$ increase in Scr 48 hours after contrast media exposure. The secondary outcomes were Scr change after exposure, defined as the difference between Scr after and before the procedure, hospital mortality and the new requirement for dialysis. The general population was defined as having a Mehran score $<11$, and the high-risk patients were defined as the population with Mehran score $\geq 11$. Subgroup analysis of lowrisk and high-risk patients was performed when possible.

\section{Statistical analysis}

Meta-analysis was performed using Review Manager V.5.3. We used $\chi^{2}$ and $\mathrm{I}^{2}$ to verify the heterogeneity among the studies. Values of the index of under $25 \%$, between $25 \%$ and $50 \%$ and over $50 \%$ indicated low, moderate and high heterogeneity, respectively. Statistical significance of heterogeneity was set at a $p$ value of 0.05 . If no substantial heterogeneity was observed $\left(\mathrm{p} \geq 0.05\right.$ or $\left.\mathrm{I}^{2}<50 \%\right)$, the fixed-effect model was used. Conversely, we presented the results with the random effect model. Mean difference and OR with the $95 \%$ CI were used to evaluate the continuous and binary variables, respectively. Sensitivity analysis was performed to detect the robustness and reliability of our results by sequentially omitting every single study. We used the funnel plot to evaluate the potential publication bias.

\section{RESULTS}

\section{Study selection and characteristics of included studies}

Figure 1 shown the literature searching process. We found 109 records from the database. After exclusion of duplicates and irrelevant studies (21 reviews, 3 case reports, 10 animal studieds, 5 comments and 45 no relevant studies), we finally enrolled seven RCTs $^{11-17}$ with a total of 1484 patients in this meta-analysis. The characteristics of the included trials were presented in table 1. All of seven included studies were performed in patients undergoing angioplasty or stenting. Five of seven trials enrolled patients from the general population ${ }^{11-15}$; one study enrolled diabetic patients, ${ }^{16}$ and the remaining six study enrolled high-risk patients. ${ }^{17}$ All the enrolled patients were prehydrated with normal saline. In addition, Aslanabadi's and Barzi's studies ${ }^{16}$ used $600 \mathrm{mg}$ $\mathrm{N}$-acetyl cysteine orally twice daily before and after the procedure. There were 740 patients in the PTX group and 744 in the control group.

\section{Primary outcome}

Data on the incidence of CIN were available in all studies included in this meta-analysis. The overall rates of CIN were $8.8 \%$ and $10.4 \%$ in the PTX groups and control groups, respectively. However, no significant reduction in the CIN rate was observed in the patients treated with PTX compared with the control groups (OR 0.81, 95\% CI 0.57 to $1.13, \mathrm{I}^{2}=0, \mathrm{p}=0.21$ ) (figure 2 ). Similarly, the incidences of CIN were also comparable between groups in the the general population subgroups (OR $0.79,95 \% \mathrm{CI}$ 0.56 to $1.12, \mathrm{I}^{2}=8 \%, \mathrm{p}=0.19$ ) (figure 3 ).

\section{Secondary outcome}

Data on Scr change after exposure were available in four of seven trials. ${ }^{13}{ }^{15-17}$ However, the study report by Eshraghi et $a l^{15}$ contributes most of the data. Thus the meta-analysis of Scr was waived. All studies reported no hospital mortality or the new requirement for dialysis during the trials. 


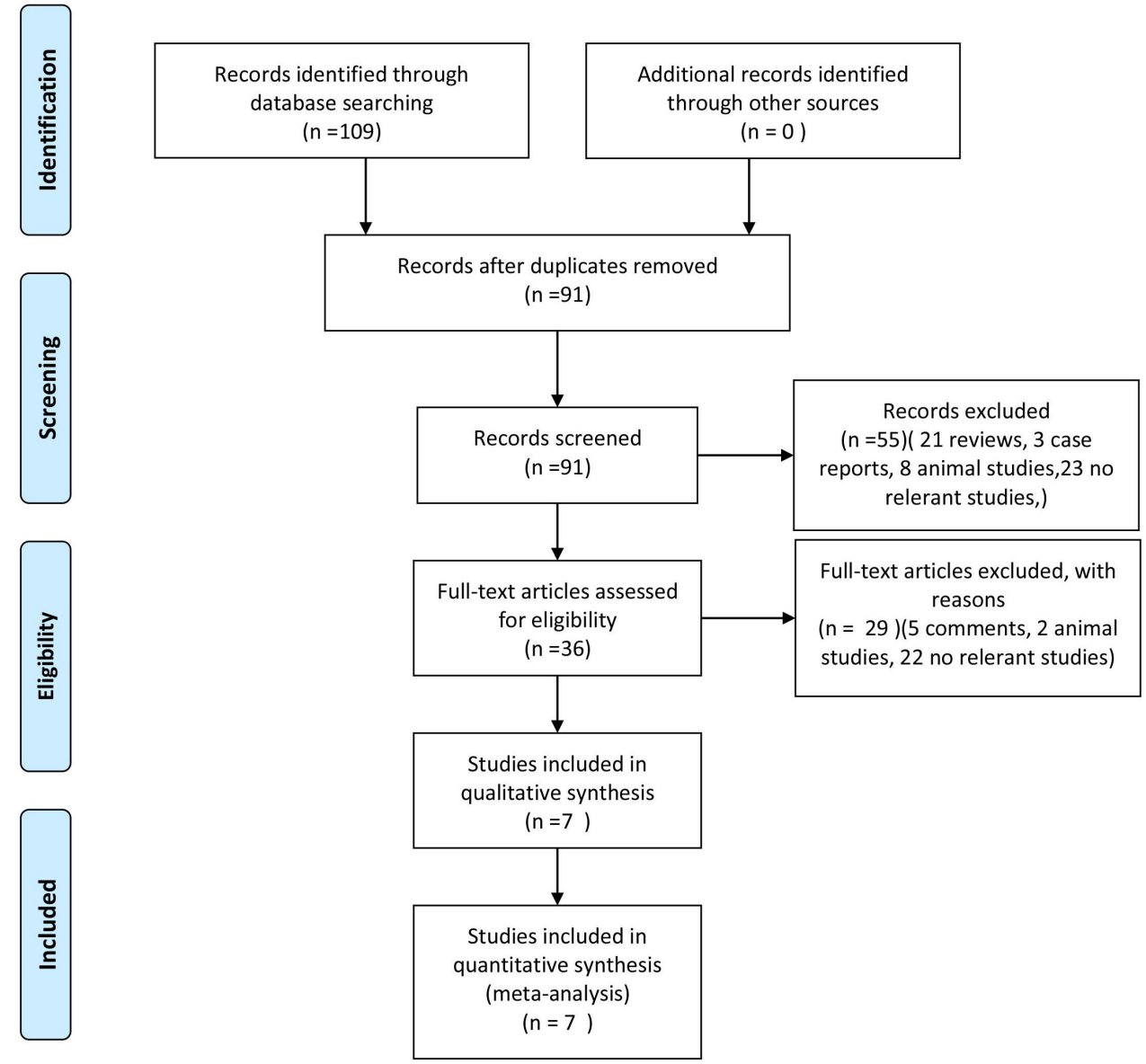

Figure 1 Flow chart of the literature searching process.

\section{Risk of bias assessment and sensitivity analysis}

The risk of bias is presented in figure 4. Six studies did not use the placebo as control and were thus not blinded. ${ }^{11-16}$ However, the development of CIN and Scr changes are objectively defined and hence less likely to bias. Outcome assessors in all trials were blinded to the trial protocol. All trials were free of selective outcome reporting.

Given the limited number of studies included in this meta-analysis, the funnel plot is not applicable for evaluating the publication bias and small-study effects.

Sensitivity analysis was performed by sequentially omitting every single study. CIN rate remained comparable between groups after excluding each trial, indicating that our results were reliable and not skewed by a single dominant study.

\section{DISCUSSION}

This is the first systematic review and meta-analysis to summarise current evidence of PTX for the prevention of CIN. The results suggested that perioperative administration of PTX to patients undergoing angioplasty or PCI significantly lower Scr increase but did not significantly reduce the development of AKI.

Our primary outcome was the incidence of CIN. There was no significant impact of PTX on this predefined primary outcome. A reasonable explanation was that although we pooled seven studies with a total of 1484 patients in this meta-analysis, the number of CIN rates was limited. Therefore, the CIs for the CIN prevention effect of PTX treatment are wide and low statistical power results in poor precision. Consequently, the results of these trials should be cautiously interpreted, and more trials with larger sample sizes are needed to evaluate the role of PTX in CIN prevention.

However, it is interesting to note that perioperative therapy with PTX did reduce Scr changes in some studies, ${ }^{13}{ }^{15-17}$ although the reduction was small (just $0.01-0.04 \mathrm{mg} / \mathrm{dL})$. In a database analysis, Weisbord and colleagues ${ }^{19}$ reported that even a small increase $(0.25-$ $0.50 \mathrm{mg} / \mathrm{dL}$ ) in postoperative Scr was associated with adverse outcomes in the coronary arteriography population. Losito and colleagues ${ }^{20}$ also showed that the increase in Scr below the AKI threshold (a 20\% increase) is still closely correlated with increased long-term mortality. It would be interesting to study whether the reduction of Scr change and adverse outcomes would show a doseresponse effect. Therefore, PTX's impact on Scr may raise growing interest in future studies as a potential agent for renoprotection to CIN. Besides, compared with de novo drug development for CIN prevention, repurposing PTX obviously saves money and time, and it can be speedily applied in clinical practice. 
Table 1 Baseline characteristics of included studies

\begin{tabular}{|c|c|c|c|c|c|c|c|c|}
\hline \multirow[b]{2}{*}{ Study ID } & \multirow[b]{2}{*}{ PTX dosage regimen } & \multirow{2}{*}{$\begin{array}{l}\text { Contrast } \\
\text { media }\end{array}$} & \multirow[b]{2}{*}{ CIN definition } & \multicolumn{2}{|c|}{ Number } & \multirow[b]{2}{*}{ Outcomes } & \multicolumn{2}{|c|}{ CIN number } \\
\hline & & & & PTX & Control & & PTX & Control \\
\hline Firouzi et $a^{11}$ & $\begin{array}{l}400 \mathrm{mg} / \text { three times a day } \\
\text { from } 24 \text { hours before to } \\
24 \text { hours after procedure. }\end{array}$ & $\begin{array}{l}\text { Ultravist/ } \\
\text { Visipaque }\end{array}$ & $\begin{array}{l}\text { Minimum } 0.5 \mathrm{mg} / \mathrm{dL} \text { or } \\
25 \% \text { increase in Scr } \\
48 \text { hours after procedure. }\end{array}$ & 140 & 146 & CIN rate & 12 & 20 \\
\hline $\begin{array}{l}\text { Shakeryan } \\
\text { et } a l^{12}\end{array}$ & $\begin{array}{l}400 \mathrm{mg} / \text { three times a day } \\
\text { from } 24 \text { hours before to } \\
24 \text { hours after procedure. }\end{array}$ & Visipaque & $\begin{array}{l}\text { Minimum } 0.5 \mathrm{mg} / \mathrm{dL} \text { or } \\
25 \% \text { increase in Scr } \\
48 \text { hours after procedure. }\end{array}$ & 164 & 164 & CIN rate & 14 & 23 \\
\hline Firouzi et $a^{14}$ & $\begin{array}{l}400 \mathrm{mg} / \text { three times a day } \\
\text { from the initiation of the } \\
\text { study to } 24 \text { hours after } \\
\text { procedure. }\end{array}$ & $\begin{array}{l}\text { Ultravist/ } \\
\text { Visipaque }\end{array}$ & $\begin{array}{l}\text { Minimum } 0.5 \mathrm{mg} / \mathrm{dL} \text { or } \\
25 \% \text { increase in Scr } \\
48 \text { hours after procedure. }\end{array}$ & 148 & 148 & CIN rate & 18 & 22 \\
\hline $\begin{array}{l}\text { Aslanabadi } \\
\text { et } a l^{16}\end{array}$ & $\begin{array}{l}1200 \mathrm{mg} \text { /once } 2-4 \text { hours } \\
\text { before ptocedure. }\end{array}$ & Visipaque & $\begin{array}{l}\text { Minimum } 0.5 \mathrm{mg} / \mathrm{dL} \text { or } \\
25 \% \text { increase in } \mathrm{Scr} \\
24 \text { hours after procedure. }\end{array}$ & 45 & 45 & $\begin{array}{l}\text { CIN rate/ } \\
\Delta \mathrm{Scr}\end{array}$ & 4 & 3 \\
\hline Barzi et al $^{17}$ & $\begin{array}{l}400 \mathrm{mg} / \text { three times a day } \\
\text { from } 24 \text { hours before to } \\
48 \text { hours after procedure. }\end{array}$ & Visipaque 320 & $\begin{array}{l}\text { Minimum } 0.5 \mathrm{mg} / \mathrm{dL} \\
\text { increase in Scr } 24 \text { hours } \\
\text { after procedure. }\end{array}$ & 55 & 55 & $\begin{array}{l}\text { CIN rate/ } \\
\Delta \mathrm{Scr}\end{array}$ & 2 & 2 \\
\hline
\end{tabular}

CIN, contrast-induced nephropathy; PTX, pentoxifylline; Scr, serum creatinine; $\Delta$ Scr, serum creatinine change before and after contrast media exposure.

Effective prevention strategies and strengthened management are the keys to reduce the CIN incidence. Choosing the optimal contrast medium, reducing contrast volume and personalised hydration are direct and effective strategies to reduce CIN. In addition, remote ischaemic preconditioning and statins have potential benefits for patients at risk for CIN, but their efficacy needs further study. ${ }^{21-27}$

CIN is a kind of AKI with complex and poorly understood mechanisms. Several studies have found that contrast media would lead to renal vascular contraction and a subsequent decrease of peripheral medullary blood flow, resulting in renal tubular anoxia and oxidative stress injury. ${ }^{28}{ }^{29}$ Besides, a higher concentration of contrast agent in the renal tubular leads to viscosity increase and results in tubule blocked.$^{30}$ PTX is a methylxanthine derivative with multiple biochemical properties and is commonly used to treat peripheral vascular disease caused by peripheral vascular disease. ${ }^{31}$ PTX is a non-selective inhibitior of phosphodiesterases, which can increase the intracellular levels of cyclic adenosine monophosphate (cAMP), leading to an improvement of oxygen delivery and a decrease of oxygen free radicals production. $^{32}$ This property, together with its capability of reducing blood viscosity and therefore increasing intraglomerular pressure, ${ }^{33} 34$ supporting the speculation on underlying renoprotective effects of PTX. Prehydration and posthydration with intravenous saline or even

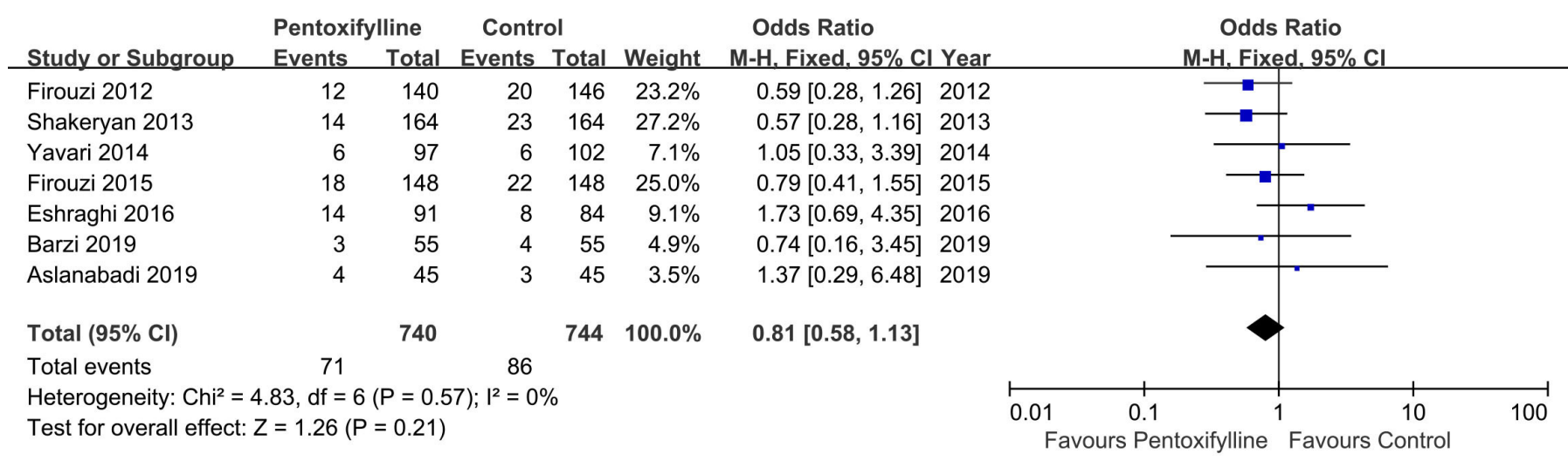

Figure 2 Evaluation of the incidence of contrast-induced nephropathy between the pentoxifylline group and the control. 


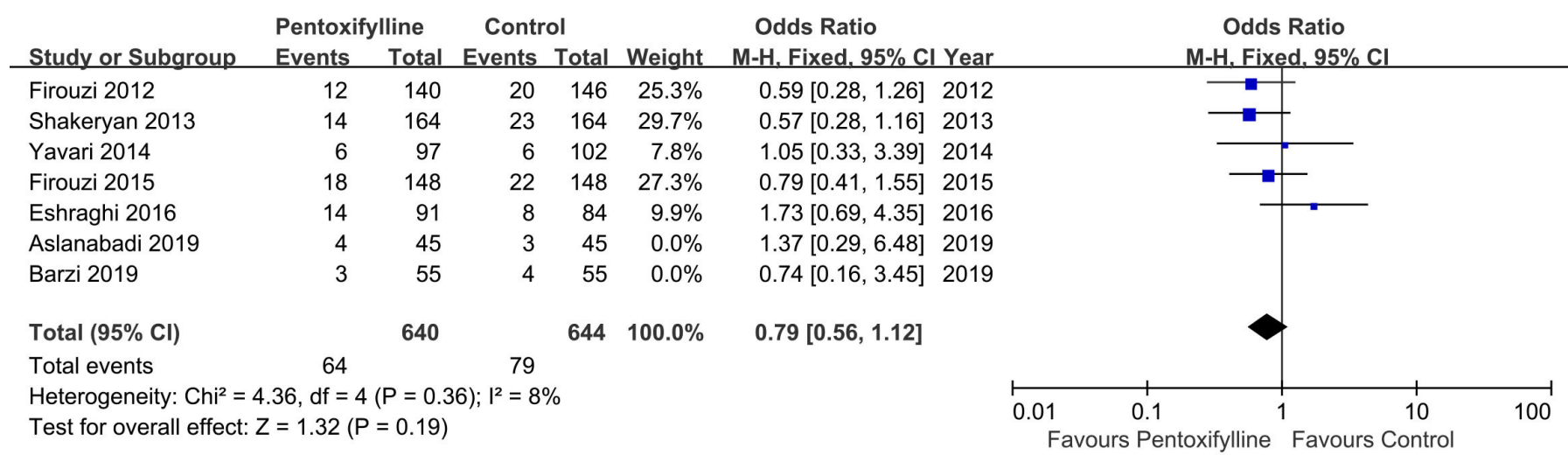

Figure 3 Evaluation of the incidence of contrast-induced nephropathy in the the general population subgroups between the pentoxifylline group and the control.

drinking a few cups of broth can also reduce the blood viscosity, and periprocedural hydration may be the most effective preventive measure for patients at risk of CIN. However, hydration may increase the risk of heart failure, arrhythmia and short-term mortality in high-risk patients.

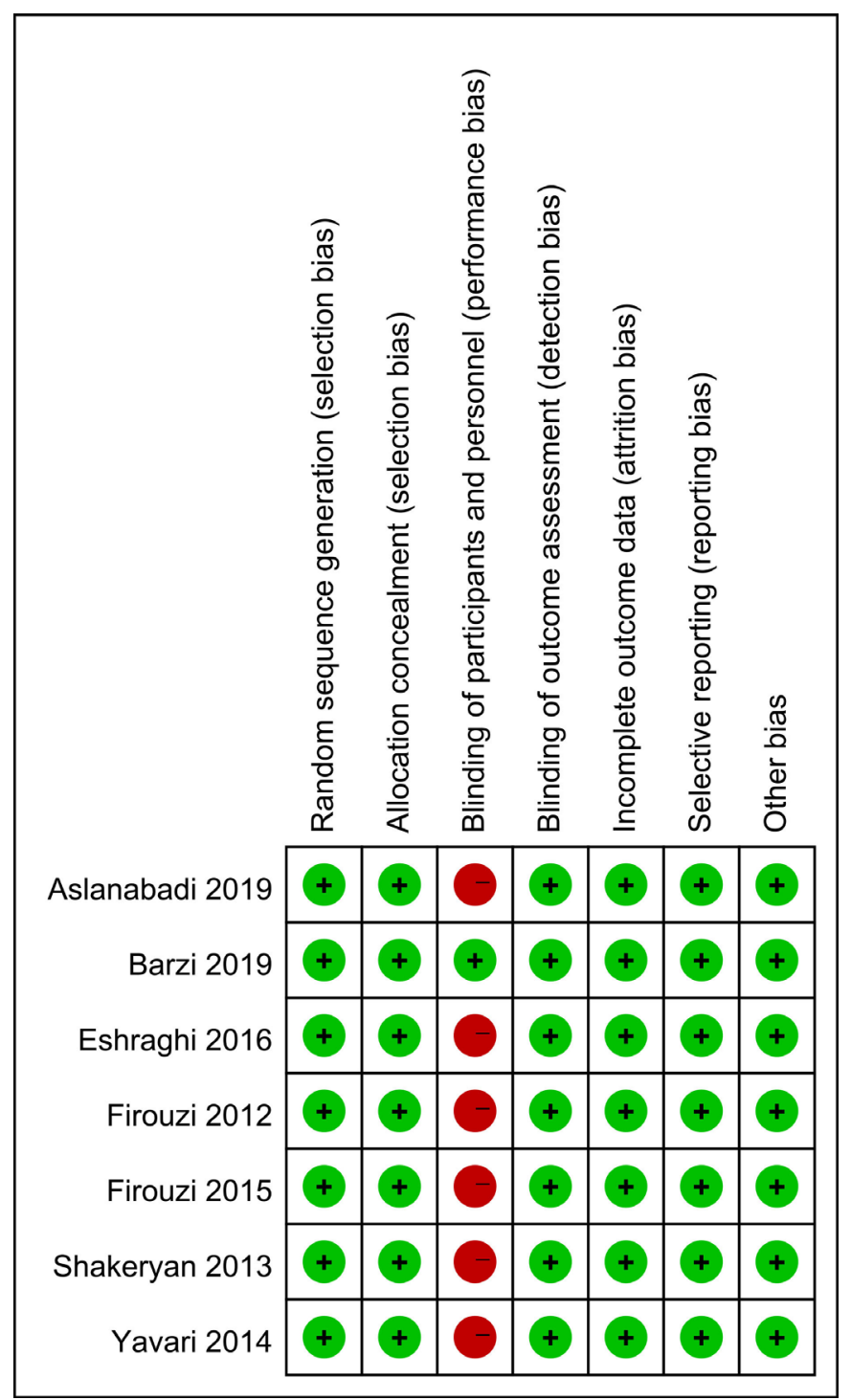

Figure 4 Risk of bias assessment of included studies.
Therefore, the reduction in blood viscosity of PTX should not be ignored.

The present study had several limitations. First, most studies used Scr to evaluate the renal function, and only three trials reported Scr changes before and after contrast media exposure. Future studies should use more sensitive markers to assess the renal function, allowing a comprehensive evaluation of the renal condition. Second, given the small number of trials included in each analysis, we failed to assess the publication bias and small study effects with funnel plots. Third, it would have been interesting to know if PTX treatment in subgroups such as the elderly and women would also be favourable compared with control. However, we failed to make a subgroup analysis because of lacking data. Fourth, some included studies were single-blinded, single-centre designs, so the possibility of bias cannot be ruled out. However, all studies used objective indicators (eg, Scr) to evaluate CIN. Nevertheless, a prospective multicentre, double-blind, placebo-controlled study would make the conclusions more convincing.

Current evidence barely strong enough to support the renoprotection of PTX to CIN. If we assume that the CIN incidence in PTX treated group is $8 \%$ and $11 \%$ in control group, with a noninferiority limit of $1.5 \%$ with power of at least $80 \%$ and one-side type 1 error rate of $2.5 \%$. More than 1000 participants are needed. More trials with larger sample sizes are needed to evaluate the role of PTX in CIN prevention.

\section{Conclusion}

Perioperative administration of PTX to patients undergoing angioplasty did not significantly reduce the development of CIN but showed some weak tendency of a lower Scr increase. Based on the available trials, the evidence does not support the administration of PTX for the prevention of CIN. More trials with larger sample sizes are needed to evaluate the role of PTX in CIN prevention.

Contributors Conception and design: DL. Administrative support: YY and WZ. Provision of study materials or patients: LW and DL. Collection and assembly of 
data: LW and DL. Data analysis and interpretation: LW and DL. Manuscript writing: all authors. Final approval of manuscript: all authors.

Funding This study was supported by the National Natural Science Foundation of China (2017YFC1308102).

Competing interests None declared.

Patient consent for publication Not required.

Provenance and peer review Not commissioned; externally peer reviewed.

Data availability statement All data relevant to the study are included in the article or uploaded as supplementary information.

Supplemental material This content has been supplied by the author(s). It has not been vetted by BMJ Publishing Group Limited (BMJ) and may not have been peer-reviewed. Any opinions or recommendations discussed are solely those of the author(s) and are not endorsed by BMJ. BMJ disclaims all liability and responsibility arising from any reliance placed on the content. Where the content includes any translated material, BMJ does not warrant the accuracy and reliability of the translations (including but not limited to local regulations, clinical guidelines, terminology, drug names and drug dosages), and is not responsible for any error and/or omissions arising from translation and adaptation or otherwise.

Open access This is an open access article distributed in accordance with the Creative Commons Attribution Non Commercial (CC BY-NC 4.0) license, which permits others to distribute, remix, adapt, build upon this work non-commercially, and license their derivative works on different terms, provided the original work is properly cited, appropriate credit is given, any changes made indicated, and the use is non-commercial. See: http://creativecommons.org/licenses/by-nc/4.0/.

ORCID iD

Dongping Li http://orcid.org/0000-0003-1009-9326

\section{REFERENCES}

1 Azzalini L, Spagnoli V, Ly HQ. Contrast-induced nephropathy: from pathophysiology to preventive strategies. Can J Cardiol 2016;32:247-55.

2 Solomon R. Contrast media: are there differences in nephrotoxicity among contrast media? Biomed Res Int 2014;2014:934947

3 Nash K, Hafeez A, Hou S. Hospital-acquired renal insufficiency. Am J Kidney Dis 2002;39:930-6.

4 Abe M, Morimoto T, Akao M, et al. Relation of contrast-induced nephropathy to long-term mortality after percutaneous coronary intervention. Am J Cardiol 2014;114:362-8.

5 Wi J, Ko Y-G, Kim J-S, et al. Impact of contrast-induced acute kidney injury with transient or persistent renal dysfunction on long-term outcomes of patients with acute myocardial infarction undergoing percutaneous coronary intervention. Heart 2011;97:1753-7.

6 Yang S-K, Duan S-B, Pan P, et al. Preventive effect of pentoxifylline on contrast-induced acute kidney injury in hypercholesterolemic rats. Exp Ther Med 2015;9:384-8.

7 Groesdonk HV, Bauer A, Kreft B, et al. Urodilatin and pentoxifylline prevent the early onset of Escherichia coli-induced acute renal failure in a model of isolated perfused rat kidney. Kidney Blood Press Res 2009;32:81-90.

8 Perkins RM, Aboudara MC, Uy AL, et al. Effect of pentoxifylline on GFR decline in CKD: a pilot, double-blind, randomized, placebocontrolled trial. Am J Kidney Dis 2009;53:606-16.

9 Navarro-González JF, Mora-Fernández C, Muros de Fuentes M, et al. Effect of pentoxifylline on renal function and urinary albumin excretion in patients with diabetic kidney disease: the PREDIAN trial. J Am Soc Nephrol 2015;26:220-9.

10 Chen P-M, Lai T-S, Chen P-Y, et al. Renoprotective effect of combining pentoxifylline with angiotensin-converting enzyme inhibitor or angiotensin II receptor blocker in advanced chronic kidney disease. J Formos Med Assoc 2014;113:219-26.

11 Firouzi A, Eshraghi A, Shakerian F, et al. Efficacy of pentoxifylline in prevention of contrast-induced nephropathy in angioplasty patients. Int Urol Nephrol 2012;44:1145-9.

12 Shakeryan F, Sanati H, Fathi $\mathrm{H}$. Evaluation of combination therapy with vitamin $\mathrm{C}$ and pentoxifylline on preventing kidney failure secondary to intravenous contrast material in coronary angioplasty. Iranian Heart J 2013;14:17-21.
13 Yavari V, Ostovan MA, Kojuri J, et al. The preventive effect of pentoxifylline on contrast-induced nephropathy: a randomized clinical trial. Int Urol Nephrol 2014;46:41-6.

14 Firouzi A, Shahsavari H, Kiani R, et al. Evaluation of pentoxifylline in the prevention of contrast-induced nephropathy in patients undergoing primary percutaneous coronary intervention. Iranian Heart J 2015;16:28-34.

15 Eshraghi A, Naranji-Sani R, Pourzand H. Pentoxifylline and prevention of contrast-induced nephropathy: is it efficient in patients with myocardial infarction undergoing coronary angioplasty? ARYA Atherosclerosis 2016;12:1-5.

16 Aslanabadi N, Afsar Gharebagh R, Moharramzadeh S, et al. Pentoxifylline for the prevention of contrast-induced nephropathy in diabetic patients undergoing angioplasty: a randomized controlled trial. Int Urol Nephrol 2019;51:699-705.

17 Barzi F, Miri R, Sadeghi R, et al. A randomized double blind placebo controlled trial examining the effects of pentoxifylline on contrast induced nephropathy reduction after percutaneous coronary intervention in high risk candidates. Iran J Pharm Res 2019;18:1040-6.

18 Higgins JPT, Savović J, Page MJ. Chapter 8: Assessing risk of bias in a randomized trial. In: Higgins JPT, Thomas J, Chandler J, et al, eds. Cochrane Handbook for systematic reviews of interventions version 6.1 (updated September 2020), 2020. www.training.cochrane.org/ handbook

19 Weisbord SD, Chen H, Stone RA, et al. Associations of increases in serum creatinine with mortality and length of hospital stay after coronary angiography. J Am Soc Nephrol 2006;17:2871-7.

20 Losito A, Nunzi E, Pittavini L, et al. Cardiovascular morbidity and long term mortality associated with in hospital small increases of serum creatinine. J Nephrol 2018;31:71-7.

21 Barrett BJ, Carlisle EJ. Metaanalysis of the relative nephrotoxicity of high- and low-osmolality iodinated contrast media. Radiology 1993;188:171-8

22 Aspelin P, Aubry P, Fransson S-G, et al. Nephrotoxic effects in highrisk patients undergoing angiography. N Engl J Med 2003;348:491-9.

23 Mehran R, Dangas GD, Weisbord SD. Contrast-associated acute kidney injury. N Engl J Med 2019;380:2146-55.

24 Qian G, Fu Z, Guo J, et al. Prevention of contrast-induced nephropathy by central venous pressure-guided fluid administration in chronic kidney disease and congestive heart failure patients. JACC Cardiovasc Interv 2016;9:89-96.

25 Brar SS, Aharonian V, Mansukhani P, et al. Haemodynamic-guided fluid administration for the prevention of contrast-induced acute kidney injury: the POSEIDON randomised controlled trial. Lancet 2014;383:1814-23.

26 Leoncini M, Toso A, Maioli M, et al. Early high-dose rosuvastatin for contrast-induced nephropathy prevention in acute coronary syndrome: results from the PRATO-ACS study (protective effect of rosuvastatin and antiplatelet therapy on contrast-induced acute kidney injury and myocardial damage in patients with acute coronary syndrome). J Am Coll Cardiol 2014;63:71-9.

27 Er F, Nia AM, Dopp H, et al. Ischemic preconditioning for prevention of contrast medium-induced nephropathy: randomized pilot RenPro trial (renal protection trial). Circulation 2012;126:296-303.

28 Mccullough PA, Stacul F, Davidson C. Contrast-induced nephropathy: clinical insights and practical guidance - a report from the CIN consensus working panel - overview. Am J Cardiol 2006;98.

29 Moreau JF, Droz D, Noel LH, et al. Tubular nephrotoxicity of watersoluble iodinated contrast media. Invest Radiol 1980;15:S54-60.

30 Sendeski M, Patzak A, Pallone TL, et al. lodixanol, constriction of medullary descending vasa recta, and risk for contrast mediuminduced nephropathy. Radiology 2009;251:697-704.

31 Seeliger E, Lenhard DC, Persson PB. Contrast media viscosity versus osmolality in kidney injury: lessons from animal studies. Biomed Res Int 2014;2014:358136

32 De Sanctis MT, Cesarone MR, Belcaro G, et al. Treatment of intermittent claudication with pentoxifylline: a 12-month, randomized trial--walking distance and microcirculation. Angiology 2002;53:S7-12

33 Lugnier C. Cyclic nucleotide phosphodiesterase (PDE) superfamily: a new target for the development of specific therapeutic agents. Pharmacol Ther 2006;109:366-98.

34 Dettelbach HR, Aviado DM. Clinical pharmacology of pentoxifylline with special reference to its hemorrheologic effect for the treatment of intermittent claudication. J Clin Pharmacol 1985;25:8-26. 